\title{
Plant-mediated interactions between two herbivores differentially affect a subsequently arriving third herbivore in populations of wild cabbage
}

\author{
A. Kroes ${ }^{1, \dagger}$, J. M. Stam ${ }^{1, \dagger}$, A. David ${ }^{2}$, W. Boland ${ }^{2}$, J. J. A. van Loon ${ }^{1}$, M. Dicke ${ }^{1}$ \& E. H. Poelman ${ }^{1}$ \\ 1 Laboratory of Entomology, Wageningen University, Wageningen, the Netherlands \\ 2 Department of Bioorganic Chemistry, Max Planck Institute for Chemical Ecology, Jena, Germany
}

\section{Keywords}

Brassica oleracea; Brevicoryne brassicae; Mamestra brassicae; multiple herbivory; phytohormones; plant defence; Plutella xylostella.

\section{Correspondence}

A. Kroes and J. M. Stam, Laboratory of Entomology, Wageningen University, PO Box 16, 6700 AA Wageningen, the Netherlands.

E-mails: annekekroes@hotmail.com and jeltje.stam@slu.se

'These authors contributed equally to this article.

Editor

K. Leiss

Received: 14 May 2016; Accepted: 1 August 2016

doi:10.1111/plb.12490

\section{ABSTRACT}

- Plants are part of biodiverse communities and frequently suffer from attack by multiple herbivorous insects. Plant responses to these herbivores are specific for insect feeding guilds: aphids and caterpillars induce different plant phenotypes. Moreover, plants respond differentially to single or dual herbivory, which may cascade into a chain of interactions in terms of resistance to other community members. Whether differential responses to single or dual herbivory have consequences for plant resistance to yet a third herbivore is unknown.

- We assessed the effects of single or dual herbivory by Brevicoryne brassicae aphids and/ or Plutella xylostella caterpillars on resistance of plants from three natural populations of wild cabbage to feeding by caterpillars of Mamestra brassicae. We measured plant gene expression and phytohormone concentrations to illustrate mechanisms involved in induced responses.

- Performance of both B. brassicae and P. xylostella was reduced when feeding simultaneously with the other herbivore, compared to feeding alone. Gene expression and phytohormone concentrations in plants exposed to dual herbivory were different from those found in plants exposed to herbivory by either insect alone. Plants previously induced by both $P$. xylostella and B. brassicae negatively affected growth of the subsequently arriving M. brassicae. Furthermore, induced responses varied between wild cabbage populations.

- Feeding by multiple herbivores differentially activates plant defences, which has plantmediated negative consequences for a subsequently arriving herbivore. Plant population-specific responses suggest that plant populations adapt to the specific communities of insect herbivores. Our study contributes to the understanding of plant defence plasticity in response to multiple insect attacks.

\section{INTRODUCTION}

Throughout the growing season, plants suffer from attack by multiple herbivorous insects. To reduce insect attack, plants protect themselves with constitutive defences like thick cell walls, a waxy epidermal cuticle or toxins (Schoonhoven et al. 2005). Furthermore, plants show defence responses induced by herbivores, for example by producing compounds that deter or repel the attackers (Schoonhoven et al. 2005), which may also affect subsequently feeding herbivores (Kessler \& Halitschke 2007). Depending on the feeding guild of the attacking insect, changes in phytohormone production, gene transcription and protein production can occur, which lead to a different regulation of plant defences (Heidel \& Baldwin 2004; de Vos et al. 2005; Bidart-Bouzat \& Kliebenstein 2011; Koo et al. 2013) and, thus to expression of a herbivore species-specific induced plant phenotype.

Phytohormonal signalling networks underlying herbivoreinduced defence responses involve, amongst others, two major phytohormones: jasmonic acid (JA) and salicylic acid (SA) (Pieterse et al. 2012). In general, JA-mediated signalling underlies plant defence responses against chewing herbivores (Stam et al. 2014). Lipoxygenases (LOXs) are important enzymes involved in JA biosynthesis (Turner et al. 2002). In cabbage, insect herbivory by Pieris rapae, Pieris brassicae or Mamestra brassicae caterpillars induced high transcript levels of BoLOX (Broekgaarden et al. 2007; Zheng et al. 2007). The importance of JA in defence responses against insects was also shown in other plant species, such as tomato (Solanum lycopersicum) (Thaler et al. 2002), milkweed (Asclepsias syriaca) (Ali \& Agrawal 2014) and tobacco (Nicotiana attenuata; reviewed in Kessler \& Baldwin 2004; Wang \& Wu 2013). Phloem feeders induce SA-regulated defences (de Vos et al. 2005). Regulation of SAmediated defences involves the expression of pathogenesisrelated $(P R)$ genes. For example, Kusnierczyk et al. (2008) investigated transcriptomic changes of Arabidopsis in response to feeding by Brevicoryne brassicae aphids and found that the expression of PR genes was significantly induced. 
Plants regulate induced defences against attacking herbivores through crosstalk between JA and SA signalling pathways (Pieterse et al. 2009). For example, in Nicotiana attenuata plants crosstalk between the JA and SA signalling pathways resulted in optimisation of defence responses (Rayapuram \& Baldwin 2007). However, insect herbivores can also interfere with JAand SA-induced defences, which can affect the outcome of interactions between plants and multiple attackers (Voelckel \& Baldwin 2004; Rodriguez-Saona et al. 2010; Mathur et al. 2013). Through these indirect plant-mediated interactions, competition between attacking herbivores is commonly found in nature, in which induced plant responses to a first herbivore may affect the resistance of plants to subsequent herbivores (Denno et al. 1995; Kaplan \& Denno 2007). Asymmetric interactions between herbivores seem to be the rule rather than the exception (Kaplan \& Denno 2007), which could lead to positive (i.e. facilitation) or negative (i.e. antagonism) effects on the performance or preference of the competing herbivore species (Kessler \& Halitschke 2007; Viswanathan et al. 2007; Erb et al. 2011; Soler et al. 2012; Ali \& Agrawal 2014; Li et al. 2014). For instance, monarch caterpillars developed faster on milkweed plants previously infested by oleander aphids, whereas the aphids developed more slowly on milkweed plants previously infested by caterpillars, which might have been JAmediated (Ali \& Agrawal 2014).

Next to the effect of one feeding herbivore on induced defences against a subsequently arriving herbivore, plant responses to dual stresses can have further ecological consequences for interactions with other community members (Utsumi et al. 2010). However, this is not yet studied in great detail. Recently, it has been shown that the specialist caterpillar Plutella xylostella gained more weight when feeding on plants previously attacked by both P. xylostella and Spodoptera litura caterpillars compared with plants previously infested by only P. xylostella. In contrast, S. litura was negatively affected when feeding on plants previously attacked by both P.xylostella and S. litura, compared with plants previously infested by only P. xylostella (Mathur et al. 2013). The effect of dual herbivory on a third herbivore suggests that interspecific competition between multiple herbivores can have consequences for the composition of whole arthropod communities assembling on the induced plant. Consequently, interactions between plants and co-occurring insects likely play important roles in natural ecosystems (Van Zandt \& Agrawal 2004; Ali \& Agrawal 2014; Poelman \& Kessler 2016). Effects of early-season herbivores on arthropod community development have indeed been shown several times (Van Zandt \& Agrawal 2004; Viswanathan et al. 2007; Poelman et al. 2010).

Studies on temporal dynamics of plant defences in response to herbivory indicate that plants may remain induced by herbivory up to several days (Voelckel \& Baldwin 2004; Underwood 2012; Mathur et al. 2013). However, induced defences were investigated after short periods of herbivory, after which the herbivore had been removed. Under natural conditions, insects likely arrive at different times on a plant, and more research is needed to study underlying molecular mechanisms in plants induced during different durations of continuous feeding and consequences for subsequent herbivores. In addition, closely related plant species differ in responses to herbivore attack, which may affect interactions between two or more insect species associated with the plant (Johnson \& Agrawal 2005; Agrawal et al. 2014). Even within plant species, populations may differ in the amount of secondary metabolites they produce (Gols et al. 2008), which has consequences for the insect communities on those populations (Newton et al. 2009b; Poelman et al. 2009; Li et al. 2014).

In the present study, we used wild Brassica oleracea plants that occur in natural populations along the coast of Dorset, UK. These plants show natural variation in the amount of constitutive and inducible secondary metabolites that act as defence compounds against herbivorous insects (Gols et al. 2008; Newton et al. 2009a). Under natural conditions, these plants are attacked by an array of herbivorous insects, amongst others the specialist aphid Brevicoryne brassicae, the specialist caterpillar P. xylostella and the generalist caterpillar Mamestra brassicae (R. Gols, personal communication; Moyes et al. 2000). Also in the Netherlands, these insects naturally occur throughout the growing season on B. oleracea cultivars (Poelman et al. 2009) and wild B. oleracea plant populations (J.M. Stam, unpublished data). The aphid B. brassicae and caterpillars of P. xylostella commonly colonise B. oleracea plants early in the season, while the caterpillars of $M$. brassicae arrive later in the season. Thus, M. brassicae caterpillars may encounter plants that have been previously attacked by P.xylostella, B. brassicae or both of these herbivores. We investigated whether herbivores from different feeding guilds, namely aphids (B. brassicae) or caterpillars ( $P$. xylostella) feeding alone or simultaneously indeed affected performance of the competing herbivore, and whether this was reflected in expression changes of marker genes involved in defence responses, i.e. $P R$ 1 and LOX (regulated by the phytohormones SA and JA, respectively). We quantified JA and SA concentrations in wild cabbage plants to assess differences in phytohormone concentrations in response to dual versus single herbivory. By using plants from different wild cabbage populations from the same area, we studied whether plant defence responses are variable across these plant populations. As a next step in the study of multiple interacting herbivores, we studied whether changes in plant resistance induced by the first two herbivores have consequences for the performance of a subsequently arriving generalist herbivore (M. brassicae). We discuss the ecological consequences of plant defence to multi-herbivory.

\section{MATERIAL AND METHODS}

\section{Plants and growth conditions}

Seeds of wild cabbage Brassica oleracea L. (Brassicaceae), from three populations in Dorset, i.e. Kimmeridge $\left(50^{\circ} 36^{\prime} \mathrm{N}\right.$, $\left.2^{\circ} 07^{\prime} \mathrm{W}\right)$, Old Harry $\left(50^{\circ} 38^{\prime} \mathrm{N}, 1^{\circ} 55^{\prime} \mathrm{W}\right)$ and Winspit $\left(50^{\circ} 35^{\prime} \mathrm{N}, 2^{\circ} 02^{\prime} \mathrm{W}\right.$ ) (Gols et al. 2008) were sown in potting soil (Lentse potgrond, Lent, The Netherlands). One week later, seedlings were transferred to individual pots (1.54 l) containing similar soil. Plants were cultivated in a glasshouse under a 16-h light:8-h dark cycle [500 $\mu \mathrm{mol}$ photons $\mathrm{m}^{-2} \cdot \mathrm{s}^{-1}$ ] at $22 \pm 3{ }^{\circ} \mathrm{C}$ and $50-70 \%$ relative humidity. Lighting from high-pressure mercury lamps was used in the glasshouse to supplement periods of low natural light. Plants were watered every other day. When plants were 4 weeks old, they were used for experiments. 


\section{Insects}

The specialist diamondback moth Plutella xylostella L. (Lepidoptera: Yponomeutidae), the specialist cabbage aphid Brevicoryne brassicae L. (Hemiptera: Aphididae) and the generalist cabbage moth Mamestra brassicae L. (Lepidoptera: Noctuidae) were obtained from stock cultures maintained at the Laboratory of Entomology, Wageningen University. All insects were reared on Brussels sprouts plants (Brassica oleracea var. gemmifera cv Cyrus) in a climate room $\left(21 \pm 1{ }^{\circ} \mathrm{C}, 50-70 \%\right.$ relative humidity, 16-h light:8-h dark cycle).

\section{Experimental set-up}

The experiments were performed in three different rounds (November 2012, January/February 2013 and March/April 2013) to obtain three biological replicates. At time points 3, 7 or 14 days after insect infestation, performance of the insects was assessed, and plant tissue for molecular defence analyses was collected. For each time point, a different set of plants was used to exclude effects of sampling tissue for molecular analyses on insect performance. Therefore, a total of 432 plants (four plants $\times$ four treatments $\times$ three time points $\times$ three $B$. oleracea populations $\times$ three rounds) were used over the entire study.

\section{Plutella xylostella and Brevicoryne brassicae performance}

At each round, 48 plants per B. oleracea population were infested with three second-instar (L2) P. xylostella caterpillars, or with five adult B. brassicae aphids, or simultaneously infested with three L2 P. xylostella caterpillars plus five adult B. brassicae aphids. Each insect was carefully placed with a small brush on the third fully expanded leaf. Clean uninfested plants were used as control. Immediately after placing the insects on a leaf, they were caged for $24 \mathrm{~h}$ using clip cages; upon removal of the clip cages the insects were allowed to move and feed freely on the plant. Empty clip cages were used for $24 \mathrm{~h}$ on leaves of control plants. Individual (infested and control) plants were covered with a gauze net supported by four wooden sticks to prevent insects from escaping.

For insect performance, individual plants were considered as the unit of biological replication. At time points 3, 7 or 14 days after infestation P. xylostella caterpillars or pupae were collected per plant and individually weighed (analytical balance: Mettler Toledo ML54/01, accuracy $=0.1 \mathrm{mg}$ ), and number of B. brassicae aphids per plant was recorded.

\section{Molecular plant defence analyses}

For gene expression and phytohormone analysis, one biological replicate consisted of eight leaf discs punched with a cork borer (diameter $=2.1 \mathrm{~cm}$ ) and pooled from four different plants.
Plant material was collected after 3, 7 or 14 days from the leaf on which the clip cage had been fixed during the first $24 \mathrm{~h}$. Because after the first $24 \mathrm{~h}$ the insects could freely move around on the plant, the transcript levels of genes measured were affected by both initial local induction as well as subsequent systemic feeding by the herbivores. Leaf discs were flashfrozen in liquid nitrogen and stored at $-80^{\circ} \mathrm{C}$ prior to analysis.

\section{Quantitative real-time PCR}

Total RNA was isolated from finely ground and homogenised leaf material with the RNeasy Plant Mini Kit (Qiagen, Hilden, Germany). RNA was treated with DNaseI (Invitrogen, Carlsbad, CA, USA) following the manufacturer's instructions. Subsequently cDNA was synthesised from RNA (adjusted to $1 \mu \mathrm{g} \cdot \mu^{-1}$ ) using iScript cDNA synthesis Kit (Bio-Rad, Hercules, CA, USA). Quantitative RT-PCR analysis was performed in a CFX96 Touch $^{\mathrm{TM}}$ Real-Time PCR Detection System (Bio$\mathrm{Rad})$. Each reaction was performed in a total volume of $25 \mu \mathrm{l}$ containing $12.5 \mu \mathrm{l}$ SYBR Green Supermix (Bio-Rad), $5 \mu \mathrm{l}$ cDNA and $1 \mu \mathrm{l}$ of $10 \mu \mathrm{M}$ forward and reverse gene specific primer pair. For each reaction, two technical replicates were performed and average values were used in the analyses. The following PCR programme including a melting curve analysis was used for all PCR reactions: $3 \mathrm{~min} 95^{\circ} \mathrm{C}$, followed by 40 cycles of $15 \mathrm{~s}$ at $95^{\circ} \mathrm{C}$ and $45 \mathrm{~s}$ at $59^{\circ} \mathrm{C}$. Relative expression of a pathogenesis-related protein $(B o P R-1)$ and lipoxygenase (BoLOX) were calculated using the $2^{-\Delta \Delta \mathrm{Ct}}$ method (Livak \& Schmittgen 2001) with the housekeeping gene glyceraldehyde3-phosphate dehydrogenase (GAPDH) (Broekgaarden et al. 2008) as internal standard.

Primer sequences (Table 1) were based on genes of Brassica oleracea var. gemmifera, namely BoLOX (GenBank accession EF123056), BoPR-1 (GenBank accession EF423806) and the reference gene BoGAPDH (GenBank accession EF123055).

\section{Phytohormone quantification}

The JA and SA phytohormone concentrations were quantified with gas chromatography-mass spectrometry as described in Schulze et al. (2006). Plant material (250 mg) was finely ground and frozen in liquid nitrogen. For quantification, $\left[9,10-{ }^{2} \mathrm{H}_{2}\right]-9,10$-dihydro-JA (250 ng) and $\left[3,4,5,6-{ }^{2} \mathrm{H}_{4}\right]-\mathrm{SA}$ (500 ng) were added as internal standards. JA concentrations were quantified by analysing samples on a Finnigan ITQ 900 (Thermo Scientific, Dreiech, Germany) device equipped with an Rtx-200MS column (30 m, $0.25 \mathrm{~mm}, 0.25 \mathrm{~mm}$; Resteck, Bad Homburg, Germany). Helium $\left(1.5 \mathrm{ml} \cdot \mathrm{min}^{-1}\right)$ served as the carrier gas. Mass spectral analysis was carried out in chemical ionisation negative (NCI) mode using methane as reagent

Table 1. Specific primer sequences used for quantitative RT-PCR analyses.

\begin{tabular}{lll}
\hline gene name & forward primer & reverse primer \\
\hline BOGAPDH & AGAGCCGCTTCCTTCAACATCATT & TGGGCACACGGAAGGACATACC \\
BoLOX & AAGGCATCGAGCTTCCCAA & TTGCTTTTCAACGGCCACTC \\
BOPR-1 & GTCAACGAGAAGGCTAACTATAACTACG & TTACACCTTGCTTTGCCACATCC \\
\hline
\end{tabular}


gas $\left(2.0 \mathrm{ml} \cdot \mathrm{min}^{-1}\right)$. Products were eluted under programmed conditions: $100^{\circ} \mathrm{C}$, increase $\left(10^{\circ} \mathrm{C} \cdot \mathrm{min}^{-1}\right)$ to $210^{\circ} \mathrm{C}$, increase $\left(1{ }^{\circ} \mathrm{C} \cdot \mathrm{min}^{-1}\right)$ to $227^{\circ} \mathrm{C}$, hold $1 \mathrm{~min}$, increase $\left(40^{\circ} \mathrm{C} \cdot \mathrm{min}^{-1}\right)$ to $290{ }^{\circ} \mathrm{C}$, hold $2 \mathrm{~min}$. The GC injector (split ratio 1:10), transfer line and ion source were set at 280,300 and $200^{\circ} \mathrm{C}$, respectively.

The SA concentrations were quantified by analysing samples on a Finnigan Trace MS quadrupole mass spectrometer (Thermo electron, Waltham, MA, USA) according to Schulze et al. (2006).

\section{Mamestra brassicae performance}

At time points 4,8 and 15 days after infestation, all 48 plants per population were sampled to investigate the effects of dual herbivory on a subsequently arriving herbivore, i.e. M. brassicae caterpillars. From each plant three leaves were excised: the leaf on which the clip cage had been fixed for the first $24 \mathrm{~h}$ and sampled for gene expression and phytohormone analyses, as well as two additional leaves which were fully unfolded and also damaged by insect feeding.

We used excised leaves to exclude that $M$. brassicae itself would induce systemic plant responses in addition to the induced plant phenotypes derived from single or dual herbivory. We thus aimed to arrest the plant phenotype as induced by treatment with B. brassicae and/or P. xylostella and used M. brassicae performance as a marker for plant quality. Future studies should explore how the more natural situation, in which also feeding by the third herbivore M. brassicae induces plant responses, would affect plant physiological responses and herbivore performance. We selected the leaf on which initial herbivores had been inoculated to link the measurements of gene expression and phytohormones directly to M. brassicae performance and added two leaves on which the initial herbivores had been feeding to provide ad libitum food to the M. brassicae caterpillars. These leaves, together representing one biological replicate, were placed in a small vial with tapwater and sealed with a cotton plug. All insects were removed when the leaves were excised. Vials containing the leaves were placed in a plastic container $(12 \times 18 \times 7 \mathrm{~cm}, \mathrm{~L} \times \mathrm{W} \times \mathrm{H})$ covered with a transparent lid with 12 small holes. In each container ten neonate (L1) M. brassicae caterpillars were carefully placed on the leaves with a small brush and allowed to feed for 6 days. Although after 6 days the leaves still looked healthy and remained turgid, any degradation in leaf quality was across all treatments and could not be excluded in this experimental design. Containers were placed in a glasshouse $\left(22 \pm 3{ }^{\circ} \mathrm{C}, 50\right.$ $70 \%$ relative humidity, 16-h light:8-h dark cycle). After 6 days of feeding, caterpillars were individually weighed on an analytical balance (Mettler Toledo ML54/01, accuracy $=0.1 \mathrm{mg}$ ). Mortality was calculated as the initial number of larvae placed on the leaves minus the number of larvae that were still alive at the moment of weighing.

\section{Statistical analysis}

The effects of herbivore treatments, time points, experimental rounds and plant populations on:

1 B. brassicae numbers, gene expression and phytohormone concentrations were analysed using a generalised linear model (GLM; forward accumulated analysis of deviance) with Poisson distribution and log link function. Time point was included as covariate, while treatment, plant population and round were included as fixed factors. An estimated dispersion parameter was included to account for residual variance. When interactions between factors were not significant, only main treatment effects are presented.

2 P. xylostella and M. brassicae caterpillar and pupal weights were analysed using a generalised linear mixed model (GLMM; sequentially adding terms to fixed model) with normal distribution and identity link function. The model included a random effect of individual plant identity and an estimated dispersion parameter to account for residual variance. When terms were not significant they were subsequently removed from the statistical model. In cases where P. xylostella caterpillar weight was lower than the accuracy of the balance $(n=31)$, they were entered with the lowest measurable weight $(0.1 \mathrm{mg})$ in the analysis. Interaction terms between treatments, time points, experimental rounds and plant populations could not be computed for $M$. brassicae data because of an insufficient number of degrees of freedom.

3 M. brassicae mortality and the fraction of $P$. xylostella pupae relative to the total of all $P$. xylostella life stages that were found per plant at each of the time points, were analysed using a GLM (forward accumulated analysis of deviance) with binomial distribution and logit link function. Binomial totals were always $10 \mathrm{M}$. brassicae larvae or were the totals of all P. xylostella life stages found per plant. An estimated dispersion parameter was included to account for residual variance.

Post-hoc tests for differences between levels of the fixed factors were analysed with a $t$-test for pair-wise differences of the means for B. brassicae numbers and M. brassicae mortality. Post-hoc comparisons for P. xylostella and M. brassicae weights, gene expression and phytohormone concentrations were analysed with an LSD test. All statistical analyses were conducted in GenStat software version 16.2 (VSN International, Hemel Hempstead, UK).

A correlation analysis was used to test for a relationship between JA and SA concentration, JA concentration and LOX expression, SA concentration and $P R-1$ expression, and $L O X$ and $P R-1$ expression in plants from each population and treatment. Excluded from analysis were all samples $(n=38$ plants over the entire study) that had unintended B. brassicae infestation.

\section{RESULTS}

\section{Performance of B. brassicae aphids and P. xylostella caterpillars}

The number of B. brassicae that accumulated per plant was $42 \%$ lower when B. brassicae aphids were feeding simultaneously with P. xylostella on the same plant, compared to B. brassicae aphids feeding alone on Kimmeridge plants (Table 2a, Fig. 1). Aphid numbers were not affected by plant population, and increased significantly with time. The experimental rounds significantly influenced $B$. brassicae numbers (Table $2 a$ ).

Simultaneous feeding by B. brassicae affected P. xylostella caterpillars negatively, depending on the time point and plant 
Table 2. Statistical tests on performance variables of insects feeding on plants from three wild Brassica oleracea plant populations, which were either undamaged or induced by Plutella xylostella caterpillars, Brevicoryne brassicae aphids, or both. (a) GLM deviance table for B. brassicae numbers, fraction of $P$. xylostella pupae and Mamestra brassicae caterpillar mortality. (b) GLMM Wald table for P. xylostella caterpillar weights, P. xylostella pupal weights, M. brassicae caterpillar weights and $M$. brassicae caterpillar weights on control plants only. Bold numbers indicate significant effects of the factor on insect performance $(\alpha=0.05)$.

\begin{tabular}{|c|c|c|c|c|c|c|c|c|c|c|c|c|c|}
\hline \multirow[b]{3}{*}{ (a) } & \multicolumn{11}{|c|}{ GLM deviance table - factors } & & \\
\hline & \multicolumn{3}{|c|}{ treatment } & \multicolumn{2}{|c|}{ plant population } & \multicolumn{3}{|c|}{ time point } & \multicolumn{3}{|c|}{ round } & \multicolumn{2}{|c|}{ total model } \\
\hline & $d f$ & deviance & $P$ & df deviance & $P$ & $d f$ & deviance & $P$ & df & deviance & $P$ & df & deviance \\
\hline B. brassicae number & 1 & 388.54 & $<0.001$ & & $n s^{a}$ & 1 & 17811.26 & $<0.001$ & 2 & 1012.50 & $<0.001$ & 204 & 23749.81 \\
\hline P. xylostella pupal fraction & & & ns & & ns & 6 & 40.96 & $<0.001$ & & & ns & 120 & 217.37 \\
\hline M. brassicae caterpillar mortality & & & ns & & ns & 8 & 157.48 & $<0.001$ & & & ns & 391 & 959.05 \\
\hline
\end{tabular}

\begin{tabular}{|c|c|c|c|c|c|c|c|c|c|c|c|c|}
\hline \multirow[b]{3}{*}{ (b) } & \multicolumn{12}{|c|}{ GLMM Wald table - factors } \\
\hline & \multicolumn{3}{|c|}{ treatment } & \multicolumn{3}{|c|}{ plant population } & \multicolumn{3}{|c|}{ time point } & \multicolumn{3}{|c|}{ round } \\
\hline & $d f$ & $\mathrm{~F}$ & $P$ & $d f$ & $\mathrm{~F}$ & $P$ & $d f$ & $\mathrm{~F}$ & $P$ & $d f$ & $\mathrm{~F}$ & $P$ \\
\hline P. xylostella caterpillar weight & 1 & 8.93 & 0.003 & 2 & 5.72 & 0.004 & 1 & 545.96 & $<0.001$ & 2 & 5.59 & 0.004 \\
\hline P. xylostella pupal weight & 1 & 0.29 & 0.593 & 2 & 0.71 & 0.494 & 1 & 2.93 & 0.091 & 2 & 2.92 & 0.060 \\
\hline M. brassicae caterpillar weight & 3 & 3.72 & 0.012 & 2 & 69.07 & $<0.001$ & 1 & 18.48 & $<0.001$ & 2 & 54.43 & $<0.001$ \\
\hline M. brassicae caterpillar weight control only & & & & 2 & 13.54 & $<0.001$ & 2 & 3.10 & 0.050 & 2 & 24.07 & $<0.001$ \\
\hline
\end{tabular}

ans: indicates a non-significant factor that was not included in the model.

Fig. 1. Brevicoryne brassicae performance. Mean number of $B$. brassicae $( \pm \mathrm{SE})$ on plants of three wild cabbage populations (Kimmeridge, Winspit and Old Harry) at 3, 7 or 14 days after single $B$. brassicae or simultaneous Plutella xylostella and $B$. brassicae infestation. Three rounds $(n=3)$ were conducted and $n=144$ individual plants were considered as the unit of biological replication per round. Bars marked with different letters are significantly different (GLM, $P<0.05)$; ns indicates no significant difference between groups.

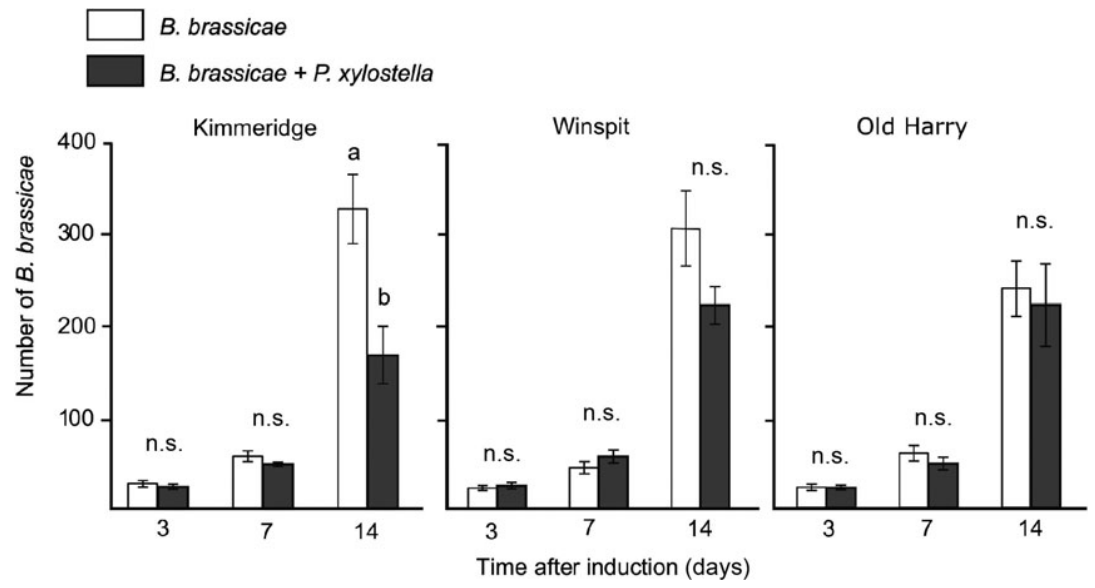

population (Table 2b). Thus, both B. brassicae and P. xylostella performance were negatively affected by simultaneous feeding by the reciprocal herbivore, and influenced by time of infestation. At 3 days after induction, there was no difference in caterpillar weights between the treatments, whereas at 7 days after induction, caterpillar weight was $16 \%$ lower when P. xylostella caterpillars were feeding simultaneously with B. brassicae aphids on the same plant, compared to $P$. xylostella caterpillars feeding alone (Fig. 2). Plant population affected P. xylostella caterpillar weights, with the highest weight at 7 days after induction reached on Old Harry plants, and lowest weight was reached on Winspit plants (Fig. 2). Experimental rounds affected $P$. xylostella caterpillar weight. Pupal weights were neither affected by the presence or absence of B. brassicae on the plant (Table $2 \mathrm{a}$ ) nor by plant population, experimental round or time point. At 14 days, the majority of the P.xylostella caterpillars had pupated and a small fraction of the pupae had eclosed.

Likewise, P.xylostella development time until pupation, measured as the fraction of pupation per time point, was not affected by simultaneous feeding by $B$. brassicae on the same plant (Table 2a). Neither differences between plant populations nor between experimental rounds were significant; the fraction of pupation increased over time.

\section{Transcriptional analyses}

Expression of the SA-responsive marker gene $P R-1$ was significantly affected by treatment, plant population and time point (Table 3a), as well as their interaction (Table 3b). Treatment, time point, plant population and round also had a significant effect on the expression of the JA-responsive marker gene $L O X$ 


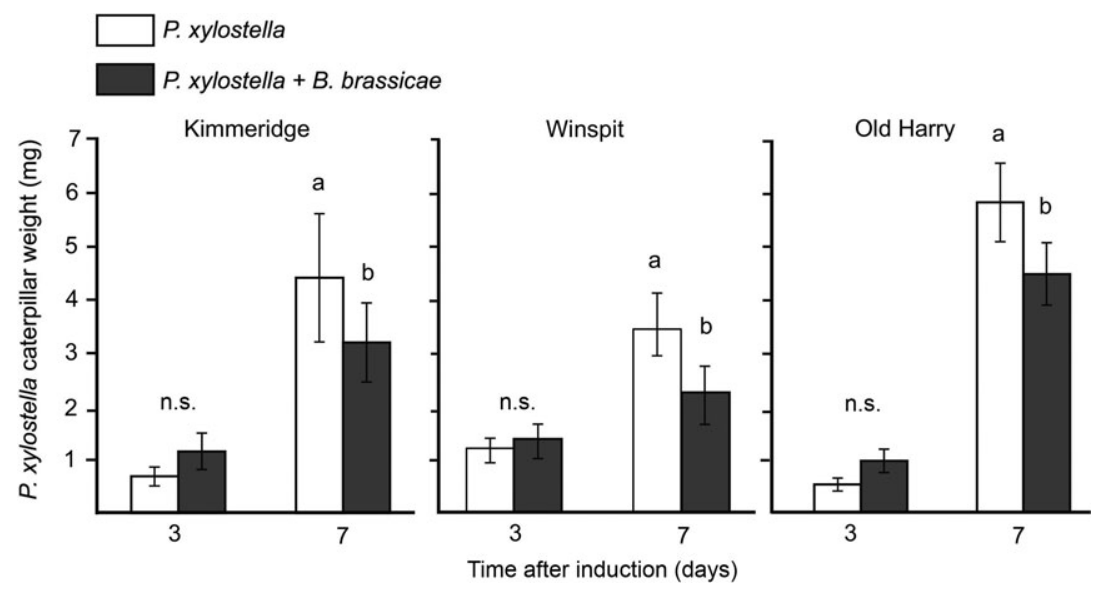

Fig. 2. Plutella xylostella performance. Mean weight (mg) of $P$. xylostella caterpillars ( \pm SE) on plants of three wild cabbage populations (Kimmeridge, Winspit and Old Harry) at 3 or 7 days after single $P$. xylostella or simultaneous P. xylostella and Brevicoryne brassicae infestation. Data for 14 days after induction are not shown here because only a few $P$. xylostella in the caterpillar stage remained at that time point, the rest pupated. Three rounds $(n=3)$ were conducted and $n=144$ individual plants were considered as the unit of biological replication per round. Bars marked with different letters are significantly different (GLMM, $P<0.05)$; ns indicates no significant difference between groups within a time point.

Table 3. Statistical tests on gene expression and hormone concentrations in plants from three wild B Brassica oleracea populations, which were either undamaged or induced by Plutella xylostella caterpillars, Brevicoryne brassicae aphids, or both. GLM deviance table for effect of Time point, Treatment, Round and Population (a) and their interaction term (b). Non- significant interaction terms were not included in the model. Bold numbers indicate significant effects $(\alpha=0.05)$.

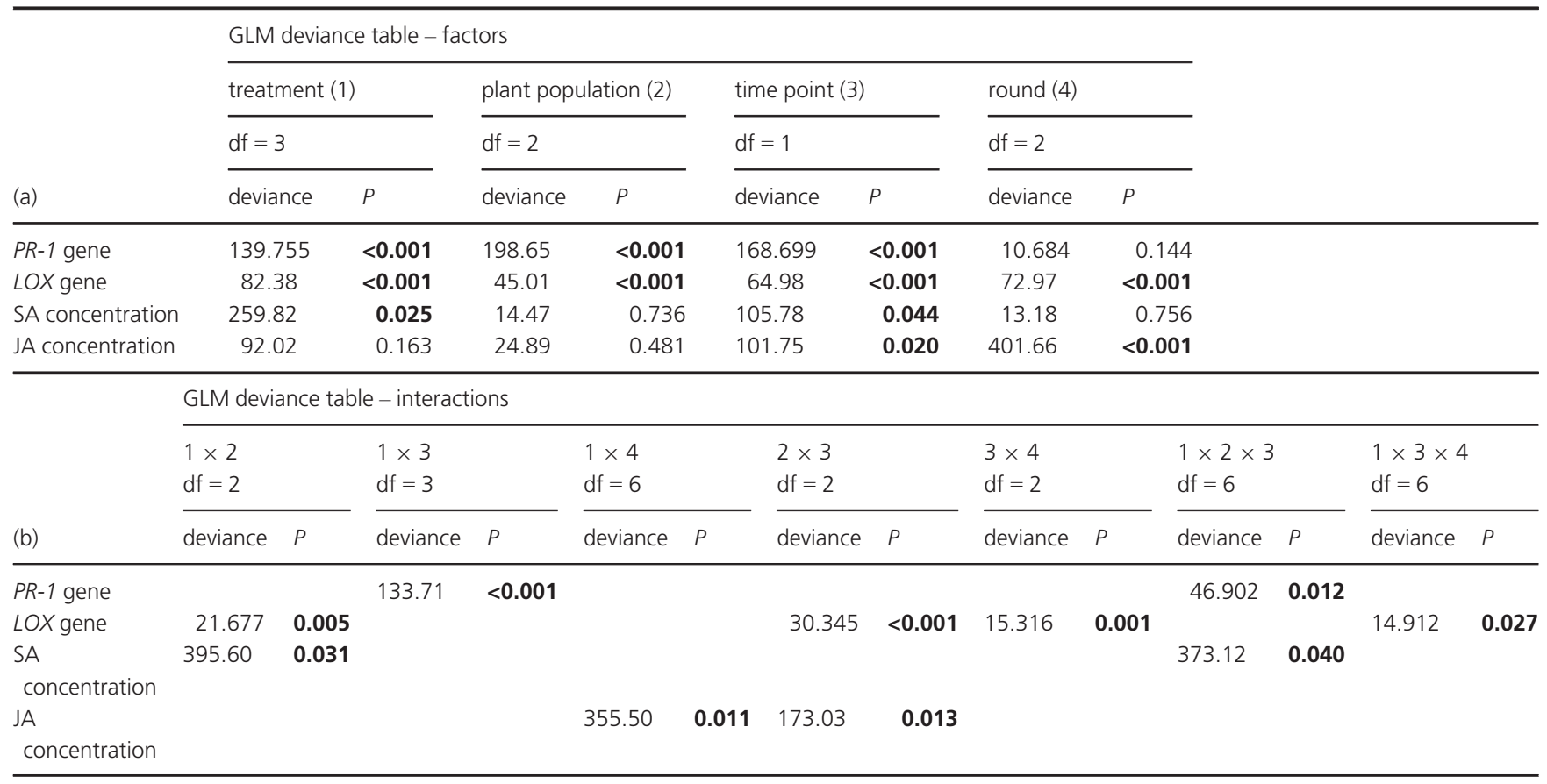

(Table 3a); however, there was no significant interaction between the factors treatment, plant population and time point (Table 3b).

Caterpillars feeding on Kimmeridge plants and simultaneous feeding by caterpillars and aphids on Old Harry plants upregulated a significantly higher proportion of $P R-1$ expression 14 days after infestation ( $>20 \%$; Fig. 3$)$. At this time point most of the P. xylostella caterpillars had pupated.

Significantly higher expression levels of $L O X$ were found in all three cabbage populations upon aphid feeding alone and simultaneous aphid and caterpillar feeding compared to control plants and plants induced with caterpillars only (Fig. 3).

In conclusion, after prolonged herbivory SA-mediated signalling is still up-regulated and dual herbivory differentially affected JA-dependent $L O X$ expression compared with plants infested by only P. xylostella caterpillars or control plants.

\section{Phytohormone analyses}

To further investigate the effect of dual herbivore attack on plant defences, the concentrations of the phytohormones JA and SA were assessed. The concentration of JA was significantly affected by time point and experimental round (Table 3a). However, JA concentrations were similar among treatments for all time points and cabbage populations (Fig. 4). There was a significant interaction between the effects of treatment, time point and plant population on SA concentration (Table 3b; GLM).

A significantly higher proportion of SA (43\%) was induced in Kimmeridge plants by aphids only or by caterpillars only 


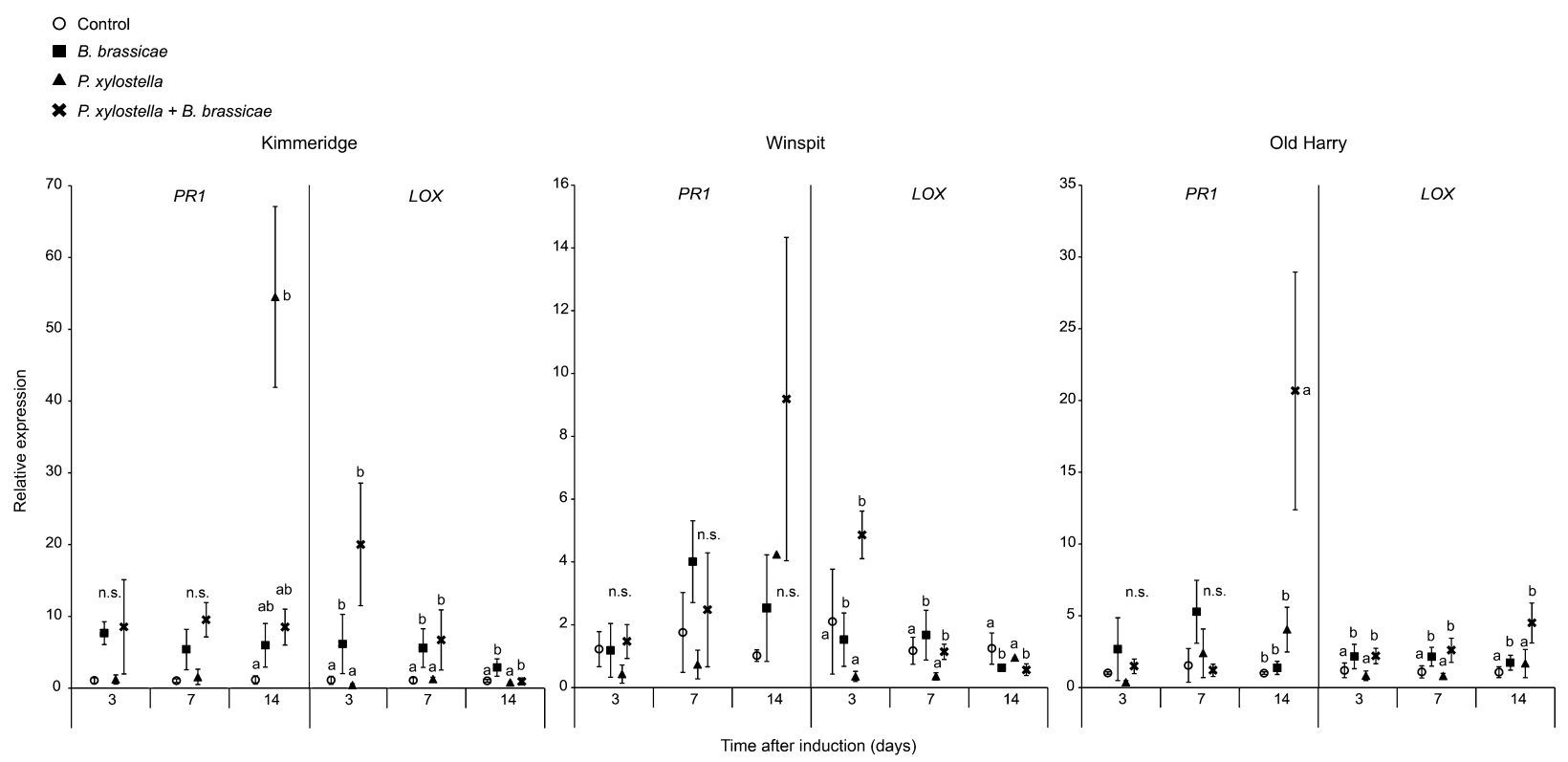

Fig. 3. Gene expression in response to single or dual insect attack. PR-1 and LOX expression in leaves of plants from wild cabbage populations (Kimmeridge, Winspit and Old Harry) at 3, 7 or 14 days after single Plutella xylostella, single Brevicoryne brassicae, simultaneous P. xylostella and B. brassicae infestation or without feeding (Control). Symbols represent means \pm SE. Three rounds $(n=3)$ were conducted and eight leaf discs were pooled from four different plants $(n=4)$ per round. Symbols marked with different letters are significantly different within a time point $(G L M, P<0.05)$; ns indicates no significant difference between groups within a time point.

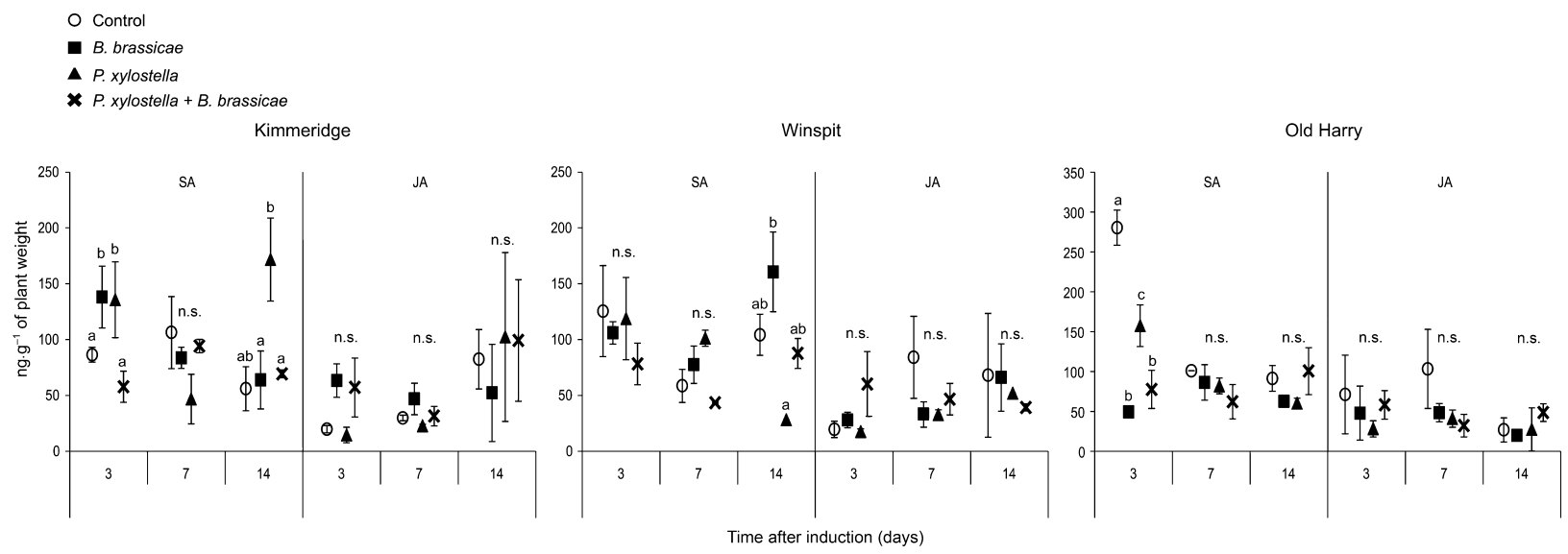

Fig. 4. Phytohormone production in response to single or dual insect attack. Salicylic acid (SA) and jasmonic acid (JA) concentrations expressed as ng per $g$ FW in wild cabbage populations (Kimmeridge, Winspit and Old Harry) at 3,7 or 14 days after single Plutella xylostella, single Brevicoryne brassicae, simultaneous $P$. xylostella and B. brassicae infestation or without feeding (Control). Symbols represent means \pm SE. Three rounds $(n=3)$ were conducted and eight leaf discs were pooled from four different plants $(n=4)$ per round. Symbols marked with different letters are significantly different within a time point $(G L M, P<0.05)$; ns indicates no significant difference between groups within a time point.

compared to plants simultaneously induced by both insects at 3 days (Fig. 4). This indicates that in Kimmeridge plants aphids and caterpillars alone induce a different SA-mediated defence response compared to both insects feeding simultaneously.

Among the three plant populations, SA concentrations differed upon insect infestation. Aphid feeding induced a significantly higher proportion of SA (83\%) in Winspit plants after 14 days compared to caterpillar-infested plants (Fig. 4). In Kimmeridge plants, 14 days after caterpillar feeding, the SA concentration was significantly induced to a higher proportion than in plants simultaneously induced by both insects and in aphid-infested plants (64\% and 69\%, respectively; Fig. 4). This is a similar activation of the SA pathway (higher $P R-1$ expression) as we had also seen in Kimmeridge plants (Fig. 3). For aphid-infested Old Harry plants, the proportion of SA was significantly lower compared to control and caterpillar-infested (69\% and 82\%, respectively) Old Harry plants 3 days after insect feeding (Fig. 4).

\section{Performance of third subsequent herbivore M. brassicae}

Plant resistance was altered by single or simultaneous feeding by the two herbivores $P$. xylostella and B. brassicae, which negatively affected the third herbivore, M. brassicae that was fed 


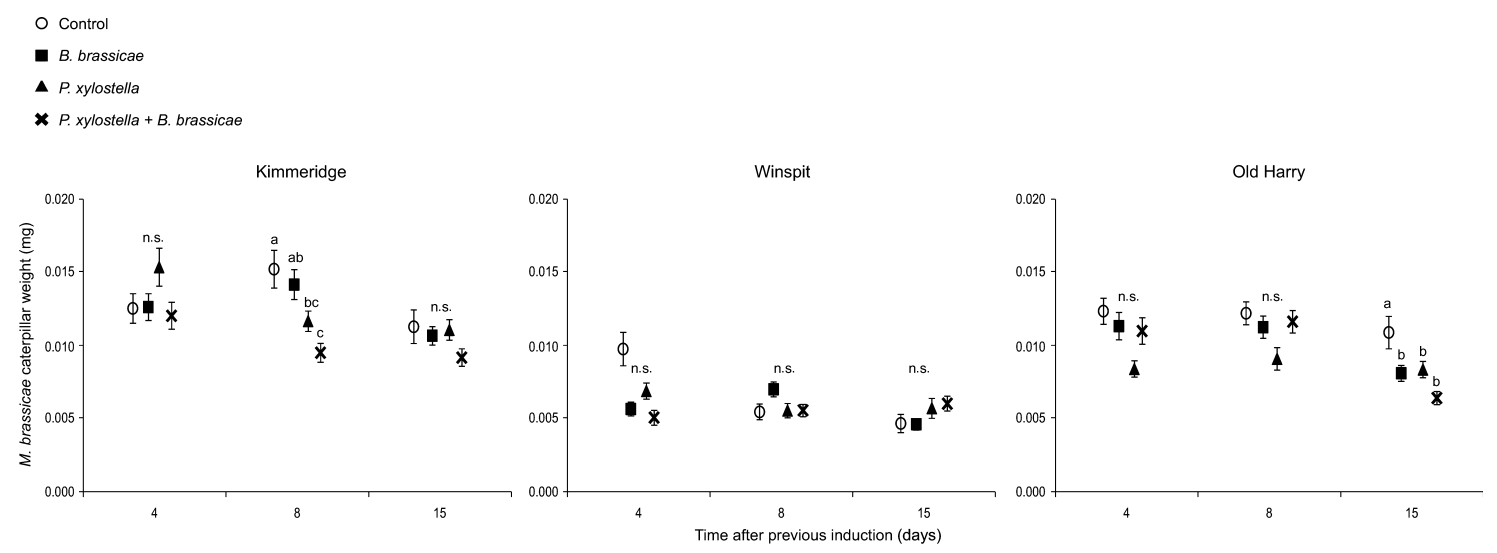

Fig. 5. Mamestra brassicae performance. Mean weight $(\mathrm{mg})$ of $M$. brassicae caterpillars ( $\pm \mathrm{SE}$ ) on plants of wild cabbage populations (Kimmeridge, Winspit and Old Harry) at 4, 8 or 15 days after previous infestation with single Brevicoryne brassicae, single Plutella xylostella or simultaneous $P$. xylostella and B. brassicae or undamaged plants (Control). Three rounds $(n=3)$ were conducted and three leaves per plant of $n=144$ individual plants were considered as the unit of biological replication per round. Symbols marked with different letters are significantly different (GLMM, $P<0.05)$; ns indicates no significant difference between groups within a time point.

with leaf tissue of the induced plants. M. brassicae performance was $19 \%$ lower on plants previously induced by both $P$. $x y$ lostella and B. brassicae compared to control plants without previous insect feeding (overall treatment effect; Table $2 b$, Fig. 5). The performance of M. brassicae on leaf tissue of undamaged plants or plants previously induced by either aphids or caterpillars did not differ from each other, indicating that only induction by the two herbivores together negatively affected the performance of M. brassicae. M. brassicae performance was affected by the length of time previous herbivores had spent feeding, as weight of $M$. brassicae caterpillars differed between the time points, mostly between 4 and 15 days, and 8 and 15 days after the start of previous herbivory. The three plant populations affected M. brassicae caterpillar weight differently, with lowest weight obtained on Winspit plants and highest weight on Kimmeridge plants. Also experimental round affected $M$. brassicae weight (Table $2 \mathrm{~b}$ ).

To verify whether the observed differences in M. brassicae weight were caused only by previous feeding by the inducing herbivores, or could also have been affected by differences in plant quality between the time points or plant populations, weight of M. brassicae caterpillars feeding on the control plants was analysed separately. M. brassicae caterpillar weight was $20 \%$ lower after feeding on leaf tissue of control plants 15 days after onset of the experiment compared to M. brassicae weight feeding on control plants 4 and 8 days after onset of the experiment (Table 2b). On leaves of Winspit control plants $M$. brassicae caterpillar weight was $47 \%$ lower compared to leaves of control plants of the two other plant populations. Weight of $M$. brassicae was also affected by the experimental round when feeding on control plants.

Mortality of $M$. brassicae caterpillars was not affected by previous induction by aphids or caterpillars (Table $2 \mathrm{a}$ ), nor was it affected by plant population or by experimental round; only at the 14-day time point was mortality higher than at either of the two other time points.

\section{DISCUSSION}

In nature, plants are frequently under attack by multiple insect herbivores. Insects feeding on plants interact indirectly through plant-mediated effects, in which initial insect attackers affect plant responses that influence subsequently feeding herbivores (Denno et al. 1995; Kaplan \& Denno 2007). In addition, it is known that induction of plant defence responses differs between dual and single herbivore attack (Voelckel \& Baldwin 2004). Importantly, the majority of herbivores will find themselves feeding on plants previously attacked by multiple insects, but little is known about the effect of multi-herbivore-induced plant phenotypes on resistance to subsequent attackers. We found that simultaneous feeding by P. xylostella and B. brassicae resulted in different plant defence-related gene expression and differences in plant hormone concentrations compared to single herbivory, and this had a negative effect on subsequently arriving M. brassicae caterpillars, depending on plant population and time point.

Here, the performance of both P. xylostella caterpillars and $B$. brassicae aphids was negatively affected by simultaneous feeding by the reciprocal herbivore. In contrast, in previous studies, positive reciprocal interactions between insects have been observed (Rieske \& Raffa 1998; Poelman et al. 2008; Soler et al. 2012; Mathur et al. 2013; Agrawal et al. 2014; Li et al. 2014). Most of those studies concerned sequential insect infestation (i.e. one herbivore after the other). Here, we introduced the two initial herbivore species simultaneously, which might explain the negative reciprocal effects on their performance that we recorded in this study. Sequential insect infestation causes a time lag between the induction by the first and a second attacker. Because plant defence signalling pathways are known to interact, a time lag could affect the interaction between defence signalling in a different way from when both attackers arrive at the same time (Erb et al. 2011; Karban 2011).

Not only the simultaneously attacking insects but also the subsequently arriving $M$. brassicae caterpillars were negatively affected by dual herbivore-induced plant resistance. These findings suggest that plant responses to herbivores attacking alone affect a herbivore arriving later in a different way to simultaneously attacking herbivore species (see also Kaplan \& Denno 2007). Such trait-mediated interaction networks (Utsumi et al. 2010) imply that herbivores can have far-reaching 
consequences for not only the plant they feed on, but also for all later arriving insects. It has been previously reported that the generalist herbivore, Spodoptera exigua, performed worse when feeding from plants previously attacked by both potato aphids and S. exigua or aphids only, compared to plants with previous $S$. exigua attack alone. This coincided with a suppression of genes that were originally up-regulated by the reciprocal herbivore and with different regulation of plant biochemistry during dual compared to single insect infestation (RodriguezSaona et al. 2010). Furthermore, Mathur et al. (2013) showed that the specialist caterpillar Plutella xylostella gained more weight when feeding on plants previously attacked by both P. xylostella and Spodoptera litura caterpillars than when feeding on plants previously attacked by only P. xylostella. However, these studies concerned only two species in conspecific or heterospecific interactions, whereas here we present the effects of two herbivores on responses to a newly arriving third insect species. In addition, the outcome of interactions between species can be herbivore species-specific (Agrawal 2000; Van Zandt \& Agrawal 2004; Uesugi et al. 2013) and density-dependent (Kroes et al. 2015). For example, plant induced responses to $P$. rapae feeding differed in the magnitude of their negative effect on performance of the generalist herbivore $M$. brassicae and the specialist $P$. xylostella and oviposition preference for the $P$. rapae-induced plant. Induced plants were preferred over undamaged plants by $P$. xylostella, whereas M. brassicae preferred undamaged plants for oviposition (Poelman et al. 2008). It remains to be identified whether the level of specificity in pair-wise herbivore interactions is further modulated in response to multi-herbivore attack or whether specific herbivore species have a prominent effect on the plant phenotype regardless of the presence of other herbivore species (Poelman \& Kessler 2016).

Our data provide further insight in how plants physiologically respond to single and dual herbivore attack by analysing the expression of defence genes and concentrations of the plant hormones SA and JA. Here, we demonstrate that plant resistance differs when induced by multiple insect attack compared to single attack, which subsequently affects the performance of successively arriving herbivores. In Kimmeridge plants, 3 days after herbivory by either aphids or caterpillars, SA was induced to significantly higher concentrations compared to plants simultaneously induced by both caterpillars and aphids. Through antagonistic or synergistic crosstalk between JA and SA, plants are able to fine-tune their defences (Pieterse et al. 2009; Thaler et al. 2012). Although a negative correlation was found between JA and SA in milkweed plants after herbivory of both monarch caterpillars and oleander aphids (Ali \& Agrawal 2014), we did not find evidence for overall suppression of JA by SA or vice versa (data not shown). However, simultaneous feeding by aphids and caterpillars resulted in a significant increase of JA-dependent LOX expression compared with plants infested by only P.xylostella caterpillars or control plants. Therefore, differential induction of JA-regulated transcriptional responses to dual insect attack could have mediated a decrease in $M$. brassicae performance because resistance to caterpillars (including $M$. brassicae - Van Dam \& Oomen 2008) is generally induced by the JA signalling pathway (de Vos et al. 2005; Stam et al. 2014). The induction of plant defence signalling affected both P.xylostella and B. brassicae performance. Therefore, JA-mediated responses not only affect caterpillars but also decrease aphid population growth. We showed that B. brassicae aphids induced both JA- and SAmediated resistance, which may affect aphid performance, depending on whether they are feeding alone or simultaneously with caterpillars (Moran et al. 2002). We found a strong correspondence between $P R-1$ expression and SA concentration (positive correlation, $r_{\mathrm{s}}=0.74, P=0.018$ ) only in Old Harry plants simultaneously infested by aphids and caterpillars. This indicates that expression of $P R-1$ can account for changes in SA concentration and, therefore, $P R-1$ expression can be used as a predictor for SA-mediated induced defences. However, direct correlation of gene expression or hormone concentrations with herbivore performance is difficult because of the different time scales at which these processes occur (Stam et al. 2014).

Nevertheless, relatively little is known about long-term effects of herbivory on the kinetics of defence-related gene expression or hormone concentrations upon multiple herbivory (de Vos et al. 2005; Kliebenstein 2014). Underwood (2012) showed that plant resistance responses might last for at least 15 days after herbivory, and had not yet decayed by the time a second herbivore arrived on the plant. However, peaks in defence-related gene expression might decay much earlier (Vos et al. 2013). We observed that 14 days after herbivory a significant up-regulation of $P R-1$ expression occurred after feeding by $P$. xylostella caterpillars only in Kimmeridge plants, or after simultaneous feeding of both caterpillars and aphids in Old Harry plants. Similar to our results, it has previously been found that P. xylostella feeding activates SA signalling in Arabidopsis and Chinese cabbage plants (Ehlting et al. 2008; Koo et al. 2013; Kroes et al. 2015). Interestingly, after 14 days the majority of the caterpillars had pupated and, thus caterpillar feeding had stopped. Elevated expression of the SA-regulated marker gene $P R-1$ in Kimmeridge plants 14 days after feeding by caterpillars could indicate priming for enhanced defence or a lag in defence response time to caterpillar attack (see Vos et al. 2013). Another possibility could be that an antagonistic effect of JA on SA-mediated PR-1 expression fell from the moment the caterpillars stopped feeding upon pupation. Furthermore, the time herbivores spent feeding may differentially affect defence responses induced by later-arriving insects. Spodoptera litura was negatively affected by previous dual P. $x y$ lostella and S. litura feeding that started 14 days earlier, but not at earlier or later time points (Mathur et al. 2013). Similar to the finding of Mathur et al. (2013) that the subsequent herbivore was negatively affected by previous insect feeding depending on the duration of herbivory, we found that M. brassicae caterpillars performed worst on plants induced by both $P$. $x y$ lostella and B. brassicae after 15 days of feeding. This indicates that the length of time first inducers spent on feeding before a subsequent herbivore arrives has an effect on the latter. However, declining plant quality over time cannot be completely excluded.

Plant species vary in their responses to herbivores, even though plant hormones and their cross-regulation are generally regarded as conserved among most of the angiosperms (Thaler et al. 2012). We observed an interaction effect between plant population and insect treatment, indicating that regulation of responses to insect feeding varies significantly within the same plant species. Differences in responses to herbivory between plant populations ( $\mathrm{Li}$ et al. 2014) or closely related plant 
species (Johnson \& Agrawal 2005; Ali \& Agrawal 2014) have been observed before. The fact that $M$. brassicae caterpillars are differentially affected by plant populations confirms previous work (Gols et al. 2008). Performance of M. brassicae caterpillars was most negatively affected by Winspit populations, which contain the highest total level of glucosinolates compared to Kimmeridge and Old Harry plants (Gols et al. 2008). This suggests that performance of M. brassicae caterpillars could also have been negatively affected by differences in nutritional quality between the plant populations, such as glucosinolates or other secondary or primary metabolites. The variation that we observed among experimental rounds could be explained by seasonally varying climate conditions that affect Brassica phenotypes, even under greenhouse conditions (Gols et al. 2007).

In conclusion, by combining ecological and molecular approaches to plant-insect interactions we show links between transcriptomic changes and insect responses. We found that changes in gene expression and phytohormone concentrations caused by dual herbivory affected a subsequently arriving third herbivore, as an example of trait-mediated interaction networks that are common in insect communities. Plant-mediated effects of responses to single herbivores are well known to affect community composition season-wide (Kessler \& Baldwin 2004; Van Zandt \& Agrawal 2004; Viswanathan et al. 2007; Poelman et al. 2010). Our study predicts that each subsequently arriving herbivore on a plant may modulate the plant phenotype and thereby affect the assembly of insects colonising the individual plant. Moreover, the order of arrival of the first colonisers may thereby have profound effects on the course of the dynamics of the insect community. Therefore, to understand how plant-insect communities are structured, we need to identify how networks of herbivore inducers and responders integrate over time (Utsumi et al. 2010; Kliebenstein 2014) and in more natural situations on intact plants with a diversity of inducing and responding insects. Such understanding will help to refine the increasingly complex plant-insect interaction models in which factors such as time course, ecological and molecular changes, multiple interacting insect attackers and plant genotype are important. Identification of these interaction networks will allow for better understanding of how plants have adapted to multi-herbivore attack in natural ecosystems (Poelman 2015; Poelman \& Kessler 2016).

\section{ACKNOWLEDGEMENTS}

This work was supported by a TOP GO grant (grant number 854.10.010 to M.D.) from The Netherlands Organization for Scientific Research (NWO). We declare that none of the authors have a conflict of interest. We thank Léon Westerd, Frans van Aggelen, André Gidding and Joop Woelke for culturing the insects and Rieta Gols for providing the B. oleracea seeds.

\section{REFERENCES}

Agrawal A.A. (2000) Specificity of induced resistance in wild radish: causes and consequences for two specialist and two generalist caterpillars. Oikos, 89, 493500.

Agrawal A.A., Hastings A.P., Patrick E.T., Knight A.C. (2014) Specificity of herbivore-induced hormonal signaling and defensive traits in five closely related milkweeds (Asclepias spp.). Journal of Chemical Ecology, 40, 717-729.

Ali J.G., Agrawal A.A. (2014) Asymmetry of plantmediated interactions between specialist aphids and caterpillars on two milkweeds. Functional Ecology, 28, 1404-1412.

Bidart-Bouzat M.G., Kliebenstein D. (2011) An ecological genomic approach challenging the paradigm of differential plant responses to specialist versus generalist insect herbivores. Oecologia, 167, 677-689.

Broekgaarden C., Poelman E.H., Steenhuis G., Voorrips R.E., Dicke M., Vosman B. (2007) Genotypic variation in genome-wide transcription profiles induced by insect feeding: Brassica oleracea-Pieris rapae interactions. BMC Genomics, 8, 239.

Broekgaarden C., Poelman E.H., Steenhuis G., Voorrips R.E., Dicke M., Vosman B. (2008) Responses of Brassica oleracea cultivars to infestation by the aphid Brevicoryne brassicae: an ecological and molecular approach. Plant, Cell and Environment, 31, 15921605.

Denno R.F., McClure M.S., Ott J.R. (1995) Interspecific interactions in phutophagous insects: competition reexamined and resurrected. Annual Review of Entomology, 40, 297-331.

Ehlting J., Chowrira S.G., Mattheus N., Aeschliman D.S., Arimura G., Bohlmann J. (2008) Comparative transcriptome analysis of Arabidopsis thaliana infested by diamond back moth (Plutella xylostella) larvae reveals signatures of stress response, secondary metabolism, and signalling. BMC Genomics, 9, 154.

Erb M., Robert C.A.M., Hibbard B.E., Turlings T.C.J. (2011) Sequence of arrival determines plantmediated interactions between herbivores. Journal of Ecology, 99, 7-15.

Gols R., Raaijmakers C.E., Van Dam N.M., Dicke M., Bukovinszky T., Harvey J.A. (2007) Temporal changes affect plant chemistry and tritrophic interactions. Basic and Applied Ecology, 8, 421-433.

Gols R., Wagenaar R., Bukovinszky T., Van Dam N.M., Dicke M., Bullock J.M., Harvey J.A. (2008) Genetic variation in defense chemistry in wild cabbages affects herbivores and their endoparasitoids. Ecology, 89, 1616-1626.

Heidel A.J., Baldwin I.T. (2004) Microarrray analysis of salicylic acid- and jasmonic acid-signalling in response of Nicotiana attenuata to attack by insects from multiple feeding guilds. Plant, Cell and Environment, 27, 1362-1373.

Johnson M.T.J., Agrawal A.A. (2005) Plant genotype and environment interact to shape a diverse arthropod community on evening primrose (Oenothera biennis). Functional Ecology, 86, 874-885.

Kaplan I., Denno R.F. (2007) Interspecific interactions in phytophagous insects revisited: a quantitative assessment of competition theory. Ecology Letters, 10, 977-994.

Karban R. (2011) The ecology and evolution of induced resistance against herbivores. Functional Ecology, 25, 339-347.

Kessler A., Baldwin I.T. (2004) Herbivore-induced plant vaccination. Part I. The orchestration of plant defenses in nature and their fitness consequences in the wild tobacco Nicotiana attenuata. The Plant Journal, 38, 639-649.

Kessler A., Halitschke R. (2007) Specificity and complexity: the impact of herbivore-induced plant responses on arthropod community structure. Current Opinion in Plant Biology, 10, 409-414.

Kliebenstein D.J. (2014) Orchestration of plant defense systems: genes to populations. Trends in Plant Science, 19, 250-255.

Koo H.-N., Cho S.-R., Moon Y.-S., Kim G.-H. (2013) Differential expression of Chinese cabbage infected by Myzus persicae and Plutella xylostella. Journal of Asia-Pacific Entomology, 16, 103-109.

Kroes A., Van Loon J.J.A., Dicke M. (2015) Densitydependent interference of aphids with caterpillarinduced defenses in Arabidopsis: involvement of phytohormones and transcription factors. Plant and Cell Physiology, 56, 98-106.

Kusnierczyk A., Winge P., Jorstad T.S., Troczynska J., Rossiter J.T., Bones A.M. (2008) Towards global understanding of plant defence against aphids - timing and dynamics of early Arabidopsis defence responses to cabbage aphid (Brevicoryne brassicae) attack. Plant, Cell and Environment, 31, 1097-1115.

Li Y., Dicke M., Harvey J.A., Gols R. (2014) Intraspecific variation in wild Brassica oleracea for aphidinduced plant responses and consequences for caterpillar-parasitoid interactions. Oecologia, 174, 853-862.

Livak K.J., Schmittgen T.D. (2001) Analysis of relative gene expression data using real-time quantitative PCR and the $2^{-\Delta \Delta C t}$ method. Methods, 25, 402-408.

Mathur V., Tytgat T.O.G., de Graaf R.M., Kalia V., Sankara Reddy A., Vet L.E.M., Van Dam N.M. (2013) Dealing with double trouble: consequences of single and double herbivory in Brassica juncea. Chemoecology, 23, 71-82.

Moran P.J., Cheng Y., Cassell J.L., Thompson G.A. (2002) Gene expression profiling of Arabidopsis thaliana in compatible plant-aphid interactions. Archives of Insect Biochemistry and Physiology, 51, 182-203.

Moyes C.L., Collin H.A., Britton G., Raybould A.F. (2000) Glucosinolates and differential herbivory in 
wild populations of Brassica oleracea. Journal of Chemical Ecology, 26, 2625-2641.

Newton E., Bullock J.M., Hodgson D. (2009a) Bottomup effects of glucosinolate variation on aphid colony dynamics in wild cabbage populations. Ecological Entomology, 34, 614-623.

Newton E.L., Bullock J.M., Hodgson D.J. (2009b) Glucosinolate polymorphism in wild cabbage (Brassica oleracea) influences the structure of herbivore communities. Oecologia, 160, 63-76.

Pieterse C.M., Leon-Reyes A., Van der Ent S., Van Wees S.C. (2009) Networking by small-molecule hormones in plant immunity. Nature Chemical Biology, 5, 308-316.

Pieterse C.M., Van der Does D., Zamioudis C., LeonReyes A., Van Wees S.C. (2012) Hormonal modulation of plant immunity. Annual Review of Cell Devevelopment Biology, 28, 489-521.

Poelman E.H. (2015) From induced resistance to defence in plant-insect interactions. Entomologia Experimentalis et Applicata, 157, 11-17.

Poelman E.H., Kessler A. (2016) Keystone herbivores and the evolution of plant defenses. Trends in Plant Science, 21, 477-485.

Poelman E.H., Broekgaarden C., Van Loon J.J.A., Dicke M. (2008) Early season herbivore differentially affects plant defence responses to subsequently colonizing herbivores and their abundance in the field. Molecular Ecology, 17, 3352-3365.

Poelman E.H., Van Dam N.M., Van Loon J.J.A., Vet L.E.M., Dicke M. (2009) Chemical diversity in Brassica oleracea affects biodiversity of insect herbivores. Ecology, 90, 1863-1877.

Poelman E.H., Van Loon J.J.A., Van Dam N.M., Vet L.E.M., Dicke M. (2010) Herbivore-induced plant responses in Brassica oleracea prevail over effects of constitutive resistance and result in enhanced herbivore attack. Ecological Entomology, 35, 240-247.

Rayapuram C., Baldwin I.T. (2007) Increased SA in NPR1-silenced plants antagonizes JA and JA-dependent direct and indirect defenses in herbivoreattacked in nature. The Plant Journal, 52, 700-715.

Rieske L.K., Raffa K.F. (1998) Interactions among insect herbivore guilds: Influence of thrips bud injury on foliar chemistry and suitability to gypsy moths. Journal of Chemical Ecology, 24, 501-523.

Rodriguez-Saona C.R., Musser R.O., Vogel H., Hum-Musser S.M., Thaler J.S. (2010) Molecular, biochemical, and organismal analyses of tomato plants simultaneously attacked by herbivores from two feeding guilds. Journal of Chemical Ecology, 36 1043-1057.

Schoonhoven L.M., Van Loon J.J.A., Dicke M. (2005) Insect-plant biology. Oxford University Press, Oxford, UK.

Schulze B., Lauchli R., Sonwa M.M., Schmidt A., Boland W. (2006) Profiling of structurally labile oxylipins in plants by in situ derivatization with pentafluorobenzyl hydroxylamine. Analytical Biochemistry, 348, 269-283.

Soler R., Badenes-Pérez F.R., Broekgaarden C., Zheng S.-J., David A., Boland W., Dicke M. (2012) Plantmediated facilitation between a leaf-feeding and a phloem-feeding insect in a brassicaceous plant: from insect performance to gene transcription. Functional Ecology, 26, 156-166.

Stam J.M., Kroes A., Li Y., Gols R., Van Loon J.J.A., Poelman E.H., Dicke M. (2014) Plant interactions with multiple insect herbivores: from community to genes. Annual Review of Plant Biology, 65 689-713.

Thaler J.S., Farag M.A., Paré P.W., Dicke M. (2002) Jasmonate-deficient plants have reduced direct and indirect defences against herbiovers. Ecology Letters, 5, 764-774.

Thaler J.S., Humphrey P.T., Whiteman N.K. (2012) Evolution of jasmonate and salicylate signal crosstalk. Trends in Plant Science, 17, 260-270.

Turner J.G., Ellis C., Devoto A. (2002) The jasmonate signal pathway. The Plant Cell, 14, S153-S164.

Uesugi A., Poelman E.H., Kessler A. (2013) A test of genotypic variation in specificity of herbivoreinduced responses in Solidago altissima L. (Asteraceae). Oecologia, 173, 1387-1396.

Underwood N. (2012) When herbivores come back: effects of repeated damage on induced resistance. Functional Ecology, 26, 1441-1449.
Utsumi S., Ando Y., Miki T. (2010) Linkages among trait-mediated indirect effects: a new framework for the indirect interaction web. Population Ecology, 52, 485-497.

Van Dam N.M., Oomen M.W.A.T. (2008) Root and shoot jasmonic acid applications differentially affect leaf chemistry and herbivore growth. Plant Signaling \& Behavior, 3, 91-98.

Van Zandt P.A., Agrawal A.A. (2004) Communitywide impacts of herbivore-induced plant responses in milkweed (Asclepias syriaca). Ecology, 85, 26162629.

Viswanathan D.V., Lifchits O.A., Thaler J.S. (2007) Consequences of sequential attack for resistance to herbivores when plants have specific induced responses. Oikos, 116, 1389-1399.

Voelckel C., Baldwin I.T. (2004) Herbivore-induced plant vaccination. Part II. Array-studies reveal the transience of herbivore-specific transcriptional imprints and a distinct imprint from stress combinations. The Plant Journal, 38, 650-663.

Vos I.A., Verhage A., Schuurink R.C., Watt L.G., Pieterse C.M., Van Wees S.C. (2013) Onset of herbivore-induced resistance in systemic tissue primed for jasmonate-dependent defenses is activated by abscisic acid. Frontiers in Plant Science, 4, 539.

de Vos M., Van Oosten V.R., Van Poecke R.M.P., Van Pelt J.A., Pozo M.J., Mueller M.J., Buchala A.J., Métraux J.-P., Van Loon L.C., Dicke M., Pieterse C.M.J. (2005) Signal signature and transcriptome changes of Arabidopsis during pathogen and insect attack. Molecular Plant-Microbe Interactions, 18, 923-937.

Wang L., Wu J. (2013) The essential role of jasmonic acid in plant-herbivore interactions - using the wild tobacco Nicotiana attenuata as a model. Journal of Genetics and Genomics, 40, 597-606.

Zheng S.J., Van Dijk J.P., Bruinsma M., Dicke M. (2007) Sensitivity and speed of induced defense of cabbage (Brassica oleracea L.): Dynamics of BoLOX expression patterns during insect and pahtogen attack. Molecular Plant-Microbe Interactions, 20, 1332-1345. 